\title{
TRANSFERÊNCIAS INTERGOVERNAMENTAIS: O PAPEL DO CONTEXTO INSTITUCIONAL PARA A SUSTENTABILIDADE DAS DÍVIDAS ESTADUAIS
}

\author{
Leandro Mendes Barbosa* \\ FABIANA ROCHA $^{\dagger}$
}

\begin{abstract}
Resumo
O objetivo deste artigo é verificar se a sustentabilidade fiscal dos estados brasileiros durante o período de 2001 a 2015 é afetada pelo sistema de transferências intergovernamentais. Os resultados indicam que a dívida pública não é sustentável e que ausência de sustentabilidade independe da inclusão/exclusão das transferências. Os efeitos, contudo, são heterogêneos. Os estados das regiões Sul e Sudeste, geralmente pagadores líquidos de transferências, não atendem a condição de sustentabilidade quando o saldo primário usual é utilizado, passando a atendê-la quando é avaliado o saldo primário exclusive as transferências. Já os demais estados demonstram grande fragilidade fiscal, não atendendo a condição de sustentabilidade sob nenhuma circunstância. Eles não mostram desempenho fiscal adequado nem mesmo quando são incluídas as transferências, apesar de serem beneficiários líquidos de recursos.
\end{abstract}

Palavras-chave: transferências, sustentabilidade, estados.

\begin{abstract}
The purpose of this paper is to verify if Brazilian states' fiscal sustainability during the period 2001 to 2015 depends on the system of intergovernmental transfers. The results indicate that the public debt is not sustainable, regardless the inclusion/exclusion of grants. The effects are, however, heterogeneous. States in the South and Southeast regions, which are liquid donors of grants, do not attend the sustainability condition for the usual primary balance, the reverse occurring when the primary balance excludes the intergovernmental transfers. The remaining states, however, show great fiscal fragility, since they do not attend the sustainability condition under no circumstance. They do not show an adequate fiscal performance even when transfers are included, although they are beneficiaries of resources.
\end{abstract}

Keywords: transfers, sustainability, states.

JEL classification: H72, H74, H77.

DOI: http://dx.doi .org/10.11606/1980-5330/ea151089

\footnotetext{
* IPE-USP

${ }^{+}$FEA-USP
} 


\section{Introdução}

A sustentabilidade fiscal, tanto em nível federal quanto das unidades federativas, sempre foi uma questão importante, embora esta última tenha recebido menos atenção da literatura ${ }^{1}$.

Para o Brasil, Mora \& Giambiagi (2007) utilizam simulações para examinar a sustentabilidade das dívidas estaduais e municipais durante o período de 1998 a 2004. Mello (2008), por sua vez, estima funções de reação fiscal para diferentes níveis de governo para o período de 1995 a 2004, enquanto Pereira (2008) utiliza técnicas de séries temporais (testes de raiz unitária, cointegração e vetores autoregressivos) para avaliar o comportamento da dívida dos estados de 1986 a 2005. Finalmente, Tabosa et. al. (2016) analisam a função de reação fiscal dos estados brasileiros entre 2006 e 2011 permitindo a possibilidade de não linearidades, ou seja, permitindo que as reações por parte das unidades federativas com maiores níveis de dívida sejam diferentes das reações das unidades com menores níveis de dívida.

Um aspecto potencialmente importante que é negligenciado na avaliação da sustentabilidade da dívida em federações é o papel desempenhado pelo sistema de transferências. Transferências fiscais entre os diferentes níveis de governo afetam seus orçamentos, com o pagamento de transferências prejudicando o desempenho fiscal e o recebimento de transferências melhorando o desempenho fiscal. Se este é de fato o caso, deixar de levar em consideração os pagamentos/recebimentos de transferências nos testes empíricos de sustentabilidade da dívida pode comprometer as conclusões.

Como é sabido, as transferências intergovernamentais representam uma importante fonte de receita para os estados brasileiros. Esse percentual gira em torno de $10 \%$ a $20 \%$ para os estados com maior PIB e chega a representar até $70 \%$ das receitas dos estados mais pobres do país. Dado isso, o contexto institucional em que ocorre a condução da política fiscal pode afetar os resultados dos testes de sustentabilidade, pois o pagamento e recebimento de transferências por parte dos estados pode alterar a restrição orçamentária intertemporal dos mesmos, modificando, por consequência, os resultados de solvência ou insolvência obtidos.

Diante disso, o objetivo deste artigo é analisar a sustentabilidade da dívida dos estados brasileiros durante o período 2001 a 2015 e verificar o papel das transferências intergovernamentais para o resultado. Para tanto são estimadas funções de reação fiscal (Bohn 1998, 2008), em que o superávit primário responde à dívida pública, sendo o saldo primário medido de duas maneiras distintas, uma incluindo e outra excluindo as receitas e despesas com transferências entre os diferentes níveis de governo ${ }^{2}$.

${ }^{1}$ Hamilton \& Flavin (1986), Trehan \& Walsh (1988, 1991), Wilcox (1989), Quintos (1995), Ahmed \& Rogers (1995), Bohn (1998, 2007, 2008), Mendoza \& Ostry (2008), Prohl \& Westerlund (2009), Byrne et al. (2011), Fincke \& Greiner (2011), Hakkio \& Rush (1991), Koester \& Priesmeier (2013), Ghosh et al. (2013). Para o Brasil, Pastore (1995), Rocha (1997), Issler \& Lima (2000), Luporini (2002), Simonassi (2007), Mendonça et. al. (2009), Bicalho \& Issler (2011), Luporini (2015), Chicoli (2015).

${ }^{2}$ A literatura empírica inicialmente usou testes de raiz unitária da dívida pública e testes de cointegração de receitas e despesas para analisar a sustentabilidade da dívida. Mais recentemente, passaram a preponderar as estimações de funções de reação fiscal como proposto por (Bohn 1998, 2008). Bohn (2007) critica os testes tradicionais que usam séries temporais mostrando que eles não são capazes de rejeitar a hipótese de sustentabilidade. 
Até onde sabemos, não existe outro trabalho que leva explicitamente em conta o papel das transferências na avaliação da sustentabilidade fiscal dos estados ou mesmo dos municípios brasileiros. Na verdade, encontramos somente dois artigos na literatura internacional que tratam desta questão. Madhavi \& Westlund (2011) avaliam o papel das regras fiscais para o equilíbrio intertemporal do orçamento dos estados e governos locais americanos. Eles encontram evidência de que as transferências são fundamentais para garantir a sustentabilidade fiscal. Potrafke \& Reischmann (2015) também concluem que as transferências são críticas para garantir a sustentabilidade dos governos estaduais da Alemanha e Estados Unidos. A política fiscal é sustentável somente quando as transferências são incluídas no superávit primário, implicando que estas estão implicitamente subsidiando as dívidas dos estados.

O sistema de transferências no Brasil é diferente e certamente mais complexo que o de outras federações. O Brasil, assim, é um bom laboratório para verificar se o que ocorre com outras federações é um resultado geral, ou se o contexto institucional é tão importante que não é possível fazer qualquer generalização sobre como ele afeta a condução da política fiscal.

Procuramos ainda por heterogeneidades nos efeitos encontrados. Como é sabido, os estados recebem, por exemplo, transferências do governo federal através do Fundo de Participação dos Estados (FPE), mas também repassam recursos aos municípios via transferências de ICMS. Os estados podem então ser classificados em dois grupos, um que é beneficiário líquido de transferências (recebe mais transferências da União do que paga de transferências aos municípios) e outro que é pagador líquido de transferências (transfere mais aos municípios do que recebe da União). Esperamos que o sistema de transferências atue no sentido de melhorar o desempenho fiscal dos estados que fazem parte do primeiro grupo, o oposto ocorrendo com os estados que compõem o segundo grupo.

O artigo está organizado em 4 Seções, além desta introdução. A Seção 2 apresenta o contexto institucional da política fiscal no Brasil e mostra como o sistema de transferências intergovernamentais pode eventualmente afetar o comportamento fiscal dos estados. A Seção 3 traz a análise empírica, discutindo o modelo econométrico, os dados e os resultados para os estados como um todo. A Seção 4 verifica a possibilidade de efeitos heterogêneos. Finalmente, a Seção 5 resume as principais conclusões.

\section{Contexto Institucional}

O federalismo fiscal brasileiro é caracterizado pela ampla utilização das transferências intergovernamentais como mecanismo de repartição de recursos entre União, estados e municípios. De acordo com o Ministério da Fazenda e o Banco Mundial, as transferências intergovernamentais representavam 1,8\% do PIB em 1980, 4,5\% do PIB em 1990, 5,8\% do PIB em 2000, 8,2\% do PIB em 2006 até atingir 11,1\% do PIB em 2014.

A Tabela 1 apresenta as transferências da União para os estados, da União para os municípios, dos estados para os municípios e as transferências dos Fundos de Desenvolvimento do Norte (FNO), do Nordeste (FNE) e do CentroOeste (FCO) e mostra como ocorre o compartilhamento das receitas entre os entes da federação. ${ }^{3}$.

\footnotetext{
${ }^{3}$ Para uma discussão cuidadosa das transferências intergovernamentais no Brasil ver Mendes
} 
Tabela 1: Transferências intergovernamentais via compartilhamento de receitas

\begin{tabular}{|c|c|c|c|}
\hline Transferência & $\begin{array}{l}\text { União para } \\
\text { os Estados }\end{array}$ & $\begin{array}{c}\text { União para } \\
\text { os Municípios }\end{array}$ & $\begin{array}{c}\text { Estados para } \\
\text { os Municípios }\end{array}$ \\
\hline FPE & $21,5 \%$ do IPI e do IR & & \\
\hline FPEX & $\begin{array}{l}7,5 \% \text { para os Esta- } \\
\text { dos exportadores }\end{array}$ & & \\
\hline CIDE & $21 \%$ da arrecadação & & \\
\hline IOF-Ouro & $30 \%$ da arrecadação & & \\
\hline $\begin{array}{c}\text { Salário- } \\
\text { Educação }\end{array}$ & $60 \%$ da arrecadação & & \\
\hline $\begin{array}{c}\text { FNO, } \\
\text { FNE e FCO }\end{array}$ & $3 \%$ do IPI e do IR & & \\
\hline Royalties & $\begin{array}{l}\text { Entre } 40 \% \text { e } 50 \% \text { da } \\
\text { arrecadação }\end{array}$ & & \\
\hline FPM & & $23,5 \%$ do IPI e do IR & \\
\hline FPEX & & $\begin{array}{l}\text { 2,5\% do IPI nos } \mathrm{Mu}- \\
\text { nicípios dos Estados } \\
\text { exportadores }\end{array}$ & \\
\hline ITR & & $50 \%$ da arrecadação & \\
\hline IOF-Ouro & & $70 \%$ da arrecadação & \\
\hline CIDE & & $\begin{array}{l}7,25 \% \text { da arrecada- } \\
\text { ção }\end{array}$ & \\
\hline Royalties & & $\begin{array}{l}\text { Entre } 30 \% \text { e } 40 \% \text { da } \\
\text { arrecadação }\end{array}$ & \\
\hline ICMS & & & $25 \%$ da arrecadação \\
\hline IPVA & & & $50 \%$ da arrecadação \\
\hline
\end{tabular}

Fonte: Secretaria de Política Econômica (SPE) do Ministério da Fazenda (MF).

Percebe-se que de um lado os estados recebem diferentes transferências do governo federal, como o FPE, as transferências advindas de recursos naturais, entre outras. De outro são obrigados constitucionalmente a pagar aos municípios transferências do ICMS e transferências do IPVA.

A Tabela 2 mostra os recebimentos pelos estados das transferências feitas pelo governo federal e os pagamentos de transferências feitos pelos estados aos municípios. Percebe-se que embora o saldo seja positivo, este fica bastante comprometido pelo montante de pagamentos realizados pelos estados aos municípios. A relação entre pagamentos e recebimentos mostra que o montante de pagamentos dos estados em transferências representa cerca de $85 \%$ do montante recebido por estes, ultrapassando a casa dos $90 \%$ em 2003 e 2013.

Para se ter uma dimensão da importância das transferências para as receitas municipais, a Figura 1 mostra o saldo primário agregado dos 26 estados e do Distrito Federal de 2001 a 2015, enquanto a Figura 2 mostra o saldo primário ajustado pelas transferências, ou seja, o saldo primário excluindo-se as transferências.

et. al. (2008). O texto não só apresenta com detalhes cada uma das transferências, como discute as características desejáveis que estas devem ter e o que fazer para que a repartição de receitas entre os diferentes níveis da federação seja melhorada, ou seja, assuma características mais próximas às definidas inicialmente como desejáveis. 
Tabela 2: Transferências do governo federal para os estados $\mathrm{x}$ transferências dos estados para os municípios (em $\mathrm{R} \$$ milhões)

\begin{tabular}{l|c|c|r|c}
\hline Ano & $\begin{array}{c}\text { Recebimentos do } \\
\text { Governo Federal }\end{array}$ & $\begin{array}{c}\text { Pagamentos aos } \\
\text { Municípios }\end{array}$ & Saldo & $\begin{array}{c}\text { Pagamentos/ } \\
\text { Recebimentos }\end{array}$ \\
\hline $\mathbf{2 0 0 2}$ & 35.787 & 30.000 & 5.787 & $83,8 \%$ \\
\hline $\mathbf{2 0 0 3}$ & 34.464 & 33.340 & 1.124 & $96,7 \%$ \\
\hline $\mathbf{2 0 0 4}$ & 43.205 & 37.767 & 5.438 & $87,4 \%$ \\
\hline $\mathbf{2 0 0 5}$ & 52.655 & 45.485 & 7.170 & $86,4 \%$ \\
\hline $\mathbf{2 0 0 6}$ & 61.781 & 46.694 & 15.087 & $75,6 \%$ \\
\hline $\mathbf{2 0 0 7}$ & 61.878 & 54.075 & 7.803 & $87,4 \%$ \\
\hline $\mathbf{2 0 0 8}$ & 80.931 & 64.004 & 16.927 & $79,1 \%$ \\
\hline $\mathbf{2 0 0 9}$ & 73.520 & 62.028 & 11.492 & $84,4 \%$ \\
\hline $\mathbf{2 0 1 0}$ & 82.642 & 72.864 & 9.779 & $88,2 \%$ \\
\hline $\mathbf{2 0 1 1}$ & 95.240 & 82.973 & 12.268 & $87,1 \%$ \\
\hline $\mathbf{2 0 1 2}$ & 98.908 & 88.564 & 10.343 & $89,5 \%$ \\
\hline $\mathbf{2 0 1 3}$ & 105.159 & 95.867 & 9.293 & $91,2 \%$ \\
\hline $\mathbf{2 0 1 4}$ & 116.131 & 103.254 & 12.876 & $88,9 \%$ \\
\hline $\mathbf{2 0 1 5}$ & 126.537 & 97.041 & 29.496 & $76,7 \%$ \\
\hline
\end{tabular}

Fonte: Secretaria do Tesouro Nacional. Elaborada pelos autores.

Figura 1: Saldo primário médio dos estados brasileiros

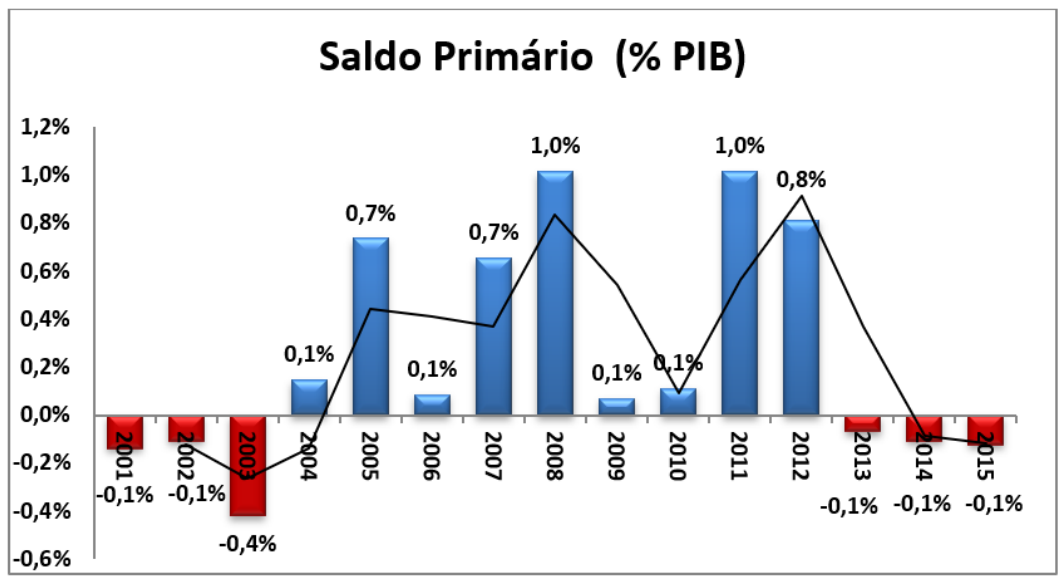

Fonte: Secretaria do Tesouro Nacional e IBGE. Elaborada pelos autores. 
Figura 2: Saldo primário dos estados, desconsiderando as transferências intergovernamentais

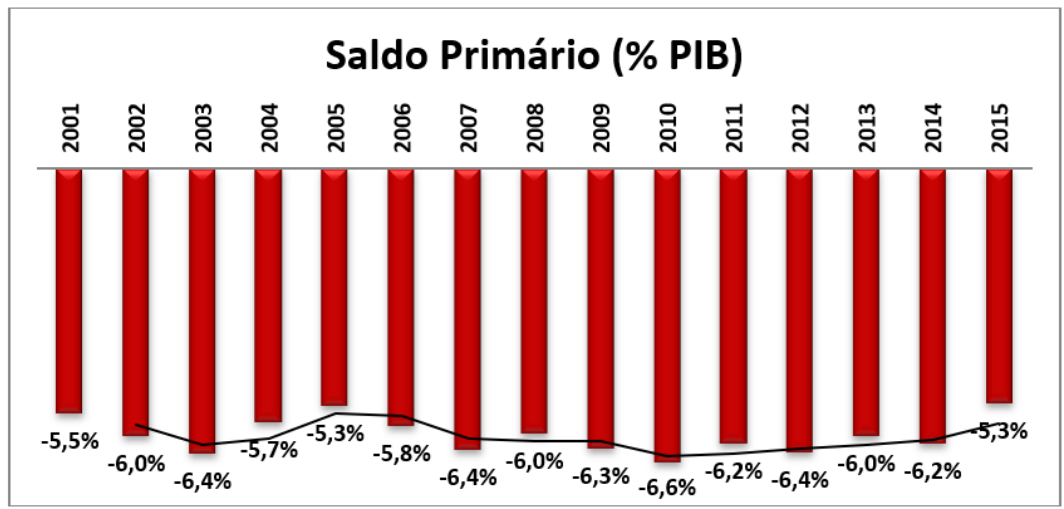

Fonte: Secretaria do Tesouro Nacional e IBGE. Elaborada pelos autores.

Quando são desconsideradas as transferências, há um déficit primário em todos os períodos, oscilando em torno de $-6,0 \%$ do PIB, ao passo que quando as transferências são levadas em conta são observados déficits em 6 dos 15 anos. Assim, pode ser o caso de que os testes empíricos indiquem que a política fiscal é sustentável somente devido às transferências.

O cenário apresentado anteriormente esconde, no entanto, a elevada heterogeneidade no grau de dependência das transferências intergovernamentais por parte dos estados brasileiros ${ }^{4}$.

A Tabela 3 mostra o percentual de receitas de transferências sobre as receitas totais para cada um dos estados das regiões Sul e Sudeste do Brasil. Os dados mostram que o percentual médio de transferências recebidas ao longo do período entre 2000 e 2015 foi de 17,2\%, ficando abaixo dos $10 \%$ em vários anos para os estados mais ricos do país, como Rio de Janeiro e São Paulo. A média nacional de transferências recebidas como percentual da receita dos estados no mesmo período foi de $36,9 \%$, valor bastante superior ao registrado nas unidades federativas das regiões Sul e Sudeste.

A Tabela 4 mostra, por outro lado, o percentual de transferências pago pelos estados do Sul e Sudeste no mesmo período. A média desses pagamentos foi de $16,2 \%$ das despesas dos estados, sendo São Paulo e Rio de Janeiro os maiores pagadores (os pagamentos de transferências respondem por 20,4\% e $21,5 \%$ de suas despesas). Esses valores são ainda bastante superiores à média nacional de despesas com transferências como percentual das despesas totais, que é de $11,8 \%$.

Os valores absolutos são apresentados na Tabela 5 em que aparece o saldo de transferências, ou seja, o total de pagamentos menos os recebimentos de transferências intergovernamentais. É possível observar que as regiões Sul

\footnotetext{
${ }^{4}$ Mendes et. al. (2008) e Ter-Minassian (2012) apresentam alguns dados sobre a dependência de estados e municípios das transferências. Os estados são menos dependentes do que os municípios, com sua receita própria representando cerca de $70 \%$ aproximadamente da receita total. Há, contudo, grande heterogeneidade. No caso dos municípios, a dependência é muito alta e generalizada, ou seja, a grande maioria dos municípios conta basicamente com as transferências como receita. Além disso, comentam que quando são consideradas todas as transferências alguns municípios/estados aparecem como beneficiários líquidos e outros como pagadores líquidos de transferências.
} 
Tabela 3: Receita de transferências intergovernamentais dos estados do Sul e Sudeste (\% das receitas totais)

\begin{tabular}{c|r|r|r|r|r|r|r|r}
\hline Ano & ES & MG & PR & \multicolumn{1}{|c|}{ RJ } & RS & SC & SP & Média \\
\hline $\mathbf{2 0 0 0}$ & 17,0 & 18,2 & 15,8 & 9,0 & 15,5 & 14,9 & 9,5 & 14,3 \\
\hline $\mathbf{2 0 0 1}$ & 23,4 & 14,7 & 24,3 & 7,9 & 14,8 & 18,5 & 9,8 & 16,2 \\
\hline $\mathbf{2 0 0 2}$ & 15,9 & 14,8 & 22,3 & 7,7 & 16,0 & 18,1 & 8,1 & 14,7 \\
\hline $\mathbf{2 0 0 3}$ & 13,4 & 13,1 & 21,1 & 6,3 & 16,8 & 21,0 & 9,1 & 14,4 \\
\hline $\mathbf{2 0 0 4}$ & 11,6 & 18,8 & 21,6 & 18,4 & 19,3 & 20,4 & 10,1 & 17,2 \\
\hline $\mathbf{2 0 0 5}$ & 11,4 & 18,8 & 22,5 & 21,8 & 19,4 & 19,1 & 10,1 & 17,6 \\
\hline $\mathbf{2 0 0 6}$ & 15,6 & 18,5 & 23,0 & 23,5 & 20,4 & 24,4 & 9,9 & 19,3 \\
\hline $\mathbf{2 0 0 7}$ & 15,4 & 19,8 & 24,8 & 8,3 & 19,8 & 19,4 & 9,1 & 16,6 \\
\hline $\mathbf{2 0 0 8}$ & 17,9 & 20,9 & 25,8 & 24,9 & 20,4 & 20,3 & 8,1 & 19,8 \\
\hline $\mathbf{2 0 0 9}$ & 20,9 & 21,2 & 26,2 & 10,4 & 18,3 & 23,4 & 7,7 & 18,3 \\
\hline $\mathbf{2 0 1 0}$ & 22,5 & 21,0 & 25,4 & 9,6 & 17,0 & 25,3 & 7,7 & 18,4 \\
\hline $\mathbf{2 0 1 1}$ & 23,5 & 19,8 & 25,6 & 9,7 & 18,0 & 24,1 & 8,0 & 18,4 \\
\hline $\mathbf{2 0 1 2}$ & 28,7 & 17,7 & 24,1 & 8,7 & 16,5 & 20,7 & 7,3 & 17,7 \\
\hline $\mathbf{2 0 1 3}$ & 30,1 & 16,7 & 22,2 & 7,9 & 15,2 & 22,3 & 7,5 & 17,4 \\
\hline $\mathbf{2 0 1 4}$ & 33,0 & 19,0 & 18,4 & 7,6 & 17,0 & 18,7 & 9,0 & 17,5 \\
\hline $\mathbf{2 0 1 5}$ & 31,5 & 18,3 & 18,8 & 9,1 & 18,0 & 18,3 & 9,3 & 17,6 \\
\hline Média & 20,8 & 18,2 & 22,6 & 11,9 & 17,6 & 20,6 & 8,8 & 17,2 \\
\hline
\end{tabular}

Fonte: Secretaria do Tesouro Nacional. Elaborada pelos autores.

Tabela 4: Despesas com transferências intergovernamentais dos estados do Sul e Sudeste (\% das despesas totais)

\begin{tabular}{c|r|r|r|r|r|r|r|r}
\hline Ano & ES & MG & PR & RJ & RS & SC & SP & Média \\
\hline $\mathbf{2 0 0 0}$ & 17,1 & 14,0 & 0,8 & 17,7 & 19,6 & 17,9 & 23,1 & 15,7 \\
\hline $\mathbf{2 0 0 1}$ & 26,6 & 21,0 & 12,4 & 23,4 & 22,4 & 25,2 & 18,3 & 21,3 \\
\hline $\mathbf{2 0 0 2}$ & 18,0 & 14,3 & 0,5 & 20,4 & 20,0 & 16,3 & 22,2 & 16,0 \\
\hline $\mathbf{2 0 0 3}$ & 18,3 & 19,9 & 0,5 & 25,9 & 17,3 & 19,7 & 21,8 & 17,6 \\
\hline $\mathbf{2 0 0 4}$ & 19,0 & 19,0 & 0,4 & 26,2 & 16,7 & 20,6 & 22,6 & 17,8 \\
\hline $\mathbf{2 0 0 5}$ & 19,7 & 18,8 & 19,7 & 25,4 & 19,8 & 20,0 & 20,7 & 20,6 \\
\hline $\mathbf{2 0 0 6}$ & 19,2 & 18,2 & 18,8 & 23,8 & 19,0 & 0,6 & 18,7 & 16,9 \\
\hline $\mathbf{2 0 0 7}$ & 19,1 & 18,7 & 19,9 & 24,5 & 18,5 & 0,8 & 20,8 & 17,5 \\
\hline $\mathbf{2 0 0 8}$ & 20,2 & 18,4 & 20,5 & 24,6 & 18,9 & 1,1 & 19,7 & 17,6 \\
\hline $\mathbf{2 0 0 9}$ & 17,4 & 17,7 & 0,4 & 25,3 & 16,8 & 1,7 & 19,0 & 14,0 \\
\hline $\mathbf{2 0 1 0}$ & 17,1 & 18,8 & 0,4 & 24,7 & 16,1 & 1,5 & 19,4 & 14,0 \\
\hline $\mathbf{2 0 1 1}$ & 18,4 & 17,4 & 20,6 & 24,6 & 17,1 & 1,5 & 19,9 & 17,1 \\
\hline $\mathbf{2 0 1 2}$ & 1,0 & 17,1 & 20,1 & 23,4 & 17,1 & 1,7 & 19,7 & 14,3 \\
\hline $\mathbf{2 0 1 3}$ & 0,8 & 16,4 & 20,6 & 15,5 & 15,9 & 1,0 & 19,0 & 12,8 \\
\hline $\mathbf{2 0 1 4}$ & 0,8 & 19,3 & 16,4 & 15,9 & 20,2 & 1,1 & 20,9 & 13,5 \\
\hline $\mathbf{2 0 1 5}$ & 0,6 & 18,5 & 19,2 & 2,0 & 19,9 & 0,9 & 20,8 & 11,7 \\
\hline Média & 14,6 & 18,0 & 11,9 & 21,5 & 18,5 & 8,2 & 20,4 & 16,2 \\
\hline Fen Ser S
\end{tabular}

Fonte: Secretaria do Tesouro Nacional. Elaborada pelos autores. 
e Sudeste e, em particular, os estados de São Paulo e do Rio de Janeiro são pagadores líquidos de recursos de transferências intergovernamentais. Dessa maneira, o sistema de transferências atua no sentido de piorar os orçamentos desses estados.

Tabela 5: Saldo de transferências dos estados das regiões Sul e Sudeste (em R \$ milhões)

\begin{tabular}{l|r|r|r|r|r|r|r|r}
\hline Ano & \multicolumn{1}{c|}{ ES } & \multicolumn{1}{|c|}{ MG } & PR & \multicolumn{1}{c|}{ RJ } & \multicolumn{1}{c|}{ RS } & SC & SP & Total \\
\hline $\mathbf{2 0 0 2}$ & -77 & -236 & 2.170 & -2.691 & -571 & 88 & -7.366 & -8.684 \\
\hline $\mathbf{2 0 0 3}$ & -175 & -1.335 & 2.232 & -4.760 & -140 & -80 & -7.294 & -11.552 \\
\hline $\mathbf{2 0 0 4}$ & -385 & -47 & 2.585 & -2.108 & 217 & -40 & -8.253 & -8.031 \\
\hline $\mathbf{2 0 0 5}$ & -520 & 45 & 410 & -1.077 & -240 & -83 & -7.977 & -9.441 \\
\hline $\mathbf{2 0 0 6}$ & -261 & 110 & 592 & -139 & 79 & 1.673 & -7.384 & -5.329 \\
\hline $\mathbf{2 0 0 7}$ & -279 & 403 & 786 & -5.731 & 380 & 1.730 & -11.225 & -13.935 \\
\hline $\mathbf{2 0 0 8}$ & -75 & 1.124 & 1.091 & 644 & 460 & 2.226 & -13.997 & -8.527 \\
\hline $\mathbf{2 0 0 9}$ & 332 & 1.459 & 5.060 & -6.479 & 445 & 2.495 & -14.702 & -11.389 \\
\hline $\mathbf{2 0 1 0}$ & 498 & 1.198 & 5.562 & -7.709 & 282 & 3.126 & -17.138 & -14.181 \\
\hline $\mathbf{2 0 1 1}$ & 733 & 1.338 & 1.358 & -8.359 & 213 & 3.459 & -18.944 & -20.202 \\
\hline $\mathbf{2 0 1 2}$ & 3.811 & 787 & 983 & -9.369 & -362 & 3.382 & -21.444 & -22.212 \\
\hline $\mathbf{2 0 1 3}$ & 3.946 & 27 & 521 & -5.496 & -517 & 4.179 & -22.775 & -20.115 \\
\hline $\mathbf{2 0 1 4}$ & 4.227 & -662 & -407 & -5.886 & -1.554 & 3.604 & -22.177 & -22.855 \\
\hline $\mathbf{2 0 1 5}$ & 3.970 & -1.540 & -542 & 4.056 & -1.693 & 3.722 & -22.426 & -14.453 \\
\hline
\end{tabular}

Fonte: Secretaria do Tesouro Nacional. Elaborada pelos autores.

Nos estados do Norte, Nordeste e Centro-Oeste a situação é bem diferente da observada nos estados do Sul e Sudeste.

A Tabela 6 apresenta os dados do percentual de receitas advindo de transferências intergovernamentais recebidas pelos estados que fazem parte dessas regiões, com exceção do Distrito Federal ${ }^{5}$. Esses estados tiveram uma média de transferências de $45 \%$ das receitas totais obtidas no período analisado, valor consideravelmente superior à média de $17 \%$ dos estados do Sul e Sudeste.

Os dados mostram que, entretanto, há estados cujo grau de dependência do sistema de transferências é enorme. No caso do Acre, Amapá e Roraima, as transferências representam mais de $70 \%$ das receitas totais em vários períodos.

A Tabela 7 apresenta os dados referentes ao pagamento de transferências intergovernamentais como percentual das despesas dos estados das regiões Norte, Nordeste e Centro-Oeste. O valor médio é de 10,8\% entre os anos 2000 e 2015, resultado inferior à média de 16,2\% dos estados das Regiões Sul e Sudeste.

A mesma situação observada nas receitas de transferências ocorre nos pagamentos das transferências. Assim, o Acre, Amapá e Roraima, além de serem os estados que mais receberam transferências, também tiveram menor média de despesas com transferências no período $(5,2 \%, 6,2 \%$ e $4,6 \%$, respectivamente).

\footnotetext{
${ }^{5} \mathrm{O}$ Distrito Federal é extremamente privilegiado no recebimento de transferências. Além dos repasses usais, se beneficia do FCDF (Fundo de Desenvolvimento do Distrito Federal). Entre 2000 e 2015, o Distrito Federal recebeu em média 24\% de suas receitas totais via transferências intergovernamentais e gastou apenas $0,04 \%$ de suas despesas totais com transferências.
} 
Tabela 6: Receita de transferências intergovernamentais dos estados do Norte, Nordeste e CentroOeste (\% das receitas totais)

\begin{tabular}{c|c|c|c|c|c|c|c|c|c|c|c|c|c|c|c|c|c|c|c|c|c|c|c}
\hline Ano & AC & AL & AM & AP & BA & CE & GO & MA & MS & MT & PA & PB & PE & PI & RN & RO & RR & SE & TO & Média \\
\hline $\mathbf{2 0 0 0}$ & 71 & 45 & 24 & 76 & 29 & 33 & 20 & 52 & 26 & 27 & 50 & 53 & 22 & 52 & 47 & 44 & 74 & 48 & 54 & 45 \\
\hline $\mathbf{2 0 0 1}$ & 71 & 50 & 23 & 70 & 26 & 38 & 19 & 57 & 21 & 29 & 44 & 42 & 24 & 56 & 41 & 42 & 67 & 48 & 51 & 43 \\
\hline $\mathbf{2 0 0 2}$ & 70 & 38 & 26 & 73 & 29 & 35 & 24 & 56 & 20 & 23 & 46 & 54 & 30 & 57 & 46 & 40 & 78 & 54 & 57 & 45 \\
\hline $\mathbf{2 0 0 3}$ & 71 & 41 & 27 & 89 & 28 & 32 & 21 & 55 & 19 & 18 & 43 & 48 & 31 & 69 & 44 & 45 & 85 & 50 & 53 & 46 \\
\hline $\mathbf{2 0 0 4}$ & 70 & 44 & 28 & 77 & 25 & 29 & 20 & 63 & 18 & 24 & 44 & 49 & 31 & 51 & 43 & 43 & 85 & 46 & 54 & 44 \\
\hline $\mathbf{2 0 0 5}$ & 68 & 54 & 29 & 82 & 33 & 33 & 21 & 63 & 21 & 27 & 46 & 49 & 33 & 57 & 48 & 45 & 82 & 52 & 64 & 48 \\
\hline $\mathbf{2 0 0 6}$ & 67 & 54 & 31 & 79 & 33 & 30 & 21 & 60 & 21 & 26 & 43 & 48 & 31 & 55 & 46 & 46 & 78 & 50 & 61 & 46 \\
\hline $\mathbf{2 0 0 7}$ & 70 & 55 & 31 & 80 & 34 & 35 & 23 & 60 & 19 & 27 & 44 & 50 & 35 & 60 & 46 & 48 & 80 & 54 & 57 & 48 \\
\hline $\mathbf{2 0 0 8}$ & 67 & 68 & 32 & 81 & 36 & 36 & 25 & 63 & 20 & 29 & 46 & 51 & 36 & 60 & 49 & 47 & 66 & 55 & 66 & 49 \\
\hline $\mathbf{2 0 0 9}$ & 55 & 51 & 26 & 78 & 36 & 32 & 25 & 59 & 20 & 27 & 43 & 51 & 34 & 52 & 44 & 46 & 66 & 53 & 58 & 45 \\
\hline $\mathbf{2 0 1 0}$ & 56 & 48 & 28 & 82 & 35 & 30 & 23 & 57 & 20 & 25 & 42 & 53 & 30 & 54 & 44 & 43 & 66 & 48 & 57 & 44 \\
\hline $\mathbf{2 0 1 1}$ & 68 & 58 & 29 & 78 & 37 & 34 & 23 & 61 & 19 & 28 & 46 & 55 & 34 & 60 & 46 & 44 & 80 & 56 & 61 & 48 \\
\hline $\mathbf{2 0 1 2}$ & 57 & 56 & 26 & 65 & 34 & 38 & 22 & 57 & 19 & 23 & 41 & 53 & 30 & 49 & 44 & 43 & 56 & 56 & 53 & 43 \\
\hline $\mathbf{2 0 1 3}$ & 61 & 50 & 27 & 65 & 32 & 36 & 22 & 49 & 17 & 25 & 39 & 50 & 28 & 54 & 41 & 43 & 55 & 52 & 56 & 42 \\
\hline $\mathbf{2 0 1 4}$ & 51 & 43 & 25 & 58 & 30 & 31 & 20 & 47 & 17 & 26 & 34 & 44 & 30 & 52 & 47 & 39 & 59 & 49 & 44 & 39 \\
\hline $\mathbf{2 0 1 5}$ & 62 & 45 & 29 & 63 & 30 & 32 & 22 & 49 & 16 & 27 & 33 & 46 & 32 & 49 & 39 & 45 & 62 & 50 & 49 & 41 \\
\hline Média & 65 & 49 & 28 & 75 & 32 & 34 & 22 & 57 & 20 & 26 & 43 & 50 & 31 & 55 & 45 & 44 & 71 & 51 & 56 & 45 \\
\hline
\end{tabular}

Fonte: Secretaria do Tesouro Nacional. Elaborada pelos autores. 
Tabela 7: Transferências intergovernamentais nos estados das regiões Norte, Nordeste e Centro-Oeste (\% das despesas totais)

\begin{tabular}{|c|c|c|c|c|c|c|c|c|c|c|c|c|c|c|c|c|c|c|c|c|}
\hline Ano & AC & AL & AM & AP & BA & CE & GO & MA & MS & MT & PA & PB & $P E$ & PI & RN & RO & RR & SE & то & Média \\
\hline 2000 & 7,3 & 9,5 & 16,9 & 5,1 & 19,7 & 13,7 & 19,3 & 7,9 & 14,2 & 16,8 & 0,6 & 10,3 & 13,6 & 15,5 & 11,5 & 12,2 & 3,9 & 9,3 & 6,7 & 11,3 \\
\hline 2001 & 7,3 & 15,2 & 2,1 & 12,7 & 1,4 & 17,8 & 1,9 & 0,0 & 0,0 & 0,0 & 13,4 & 25,0 & 14,3 & 13,9 & 31,5 & 0,0 & 0,0 & 15,7 & 0,0 & 9,1 \\
\hline 2002 & 4,0 & 13,5 & 14,8 & 5,3 & 14,3 & 10,9 & 17,5 & 17,6 & 17,0 & 17,1 & 13,6 & 9,9 & 11,5 & 0,0 & 12,5 & 11,1 & 5,2 & \begin{tabular}{|l}
9,7 \\
\end{tabular} & 6,5 & 11,1 \\
\hline 2003 & 4,8 & 15,2 & 16,9 & 4,8 & 14,1 & 17,6 & 19,4 & 17,9 & 16,6 & 21,2 & 14,8 & 9,9 & 13,1 & 7,8 & 13,5 & 14,8 & 4,6 & 12,8 & 7,9 & $\overline{13,0}$ \\
\hline 2004 & 5,5 & 15,7 & 16,5 & 4,8 & 15,0 & 18,5 & 16,8 & 10,4 & 16,8 & 19,6 & 14,1 & 10,2 & 13,1 & 8,0 & 12,8 & 14,6 & 5,8 & 10,1 & 8,0 & 12,4 \\
\hline 2005 & 5,8 & 9,5 & 16,5 & 5,6 & 15,0 & 18,7 & 15,9 & 11,9 & 18,4 & 17,3 & 14,6 & 10,3 & 13,1 & 8,8 & 12,8 & 14,2 & 5,2 & 10,5 & 8,5 & 12,2 \\
\hline 2006 & 5,0 & 11,0 & 16,9 & 5,6 & 14,8 & 16,6 & 16,4 & 12,2 & 18,6 & 17,3 & 14,1 & 10,3 & 14,8 & 8,9 & 12,7 & 14,5 & 5,3 & 9,9 & 8,4 & 12,3 \\
\hline 2007 & 5,4 & 11,9 & 17,0 & 5,7 & 14,8 & 19,6 & 16,1 & 12,3 & 19,3 & 17,2 & 14,0 & 10,7 & 13,8 & 2,9 & 11,6 & 14,6 & 5,5 & 11,5 & 8,4 & 12,2 \\
\hline 2008 & 5,2 & 12,2 & 16,8 & 5,8 & 14,3 & 19,4 & 17,1 & 12,0 & 19,0 & 16,9 & 13,2 & 10,5 & 13,4 & 0,2 & 11,8 & 14,6 & 5,1 & 10,6 & 8,1 & 11,9 \\
\hline 2009 & 4,2 & 10,8 & 14,5 & 6,7 & 13,2 & 17,3 & 16,5 & 10,2 & 17,5 & 15,3 & 13,2 & 0,4 & 12,5 & 0,3 & 11,2 & 13,1 & 5,4 & 9,7 & 7,9 & 10,5 \\
\hline 2010 & 4,5 & 12,8 & 16,2 & 5,8 & 13,7 & 17,5 & 15,4 & 11,2 & 17,0 & 15,6 & 13,1 & 0,5 & 13,0 & 0,3 & 12,2 & 14,7 & 5,8 & 10,1 & 8,0 & 11,0 \\
\hline 2011 & 4,9 & 13,1 & 16,0 & 5,4 & 13,9 & 18,5 & 1,6 & $\overline{11,0}$ & 17,5 & 15,4 & 14,1 & 1,4 & 13,4 & 0,1 & 12,6 & 15,2 & 0,0 & 1,2 & 8,8 & 9,7 \\
\hline 2012 & 4,9 & 12,5 & 15,5 & 5,6 & 13,4 & 13,0 & 1,1 & 11,6 & 17,6 & 14,2 & 14,2 & 0,8 & 12,6 & 0,2 & 12,9 & 14,4 & 5,1 & 1,6 & 8,8 & 9,5 \\
\hline 2013 & 4,6 & 12,6 & 14,6 & 5,3 & 14,2 & 13,8 & 1,1 & 8,7 & 17,0 & 1,7 & 14,3 & 1,0 & 12,6 & 0,4 & 12,2 & 13,3 & 3,9 & 1,3 & 7,9 & 8,5 \\
\hline 2014 & 4,7 & 11,6 & 15,2 & 6,2 & 14,8 & 13,9 & 0,7 & 11,6 & 18,1 & 1,7 & 15,0 & 0,7 & 14,4 & 0,8 & 14,0 & 15,2 & 5,6 & 1,2 & 8,5 & 9,2 \\
\hline 2015 & 5,7 & 12,7 & 15,6 & 8,5 & 14,7 & 14,8 & 0,8 & 11,0 & 18,7 & 2,0 & 14,7 & 0,8 & 14,9 & 1,4 & 13,0 & 2,6 & 6,4 & 1,2 & 9,5 & 8,9 \\
\hline Média & 5,2 & 12,5 & $\mid 15,1$ & 6,2 & 13,8 & 16,4 & 11,2 & 11,1 & 16,5 & 13,1 & 13,2 & 7,0 & 13,4 & 4,3 & 13,7 & \begin{tabular}{|l|}
12,4 \\
\end{tabular} & 4,6 & 7,9 & 7,6 & 10,8 \\
\hline
\end{tabular}

Fonte: Secretaria do Tesouro Nacional. Elaborada pelos autores. 
Finalmente, a Tabela 8 mostra o saldo de transferências dos estados do Norte, Nordeste e Centro-Oeste. Os dados indicam que esses estados foram recebedores líquidos de transferências em todo o período entre 2002 e 2015, exceções feitas ao estado de Mato Grosso no ano de 2003 e ao Mato Grosso do Sul entre 2013 e 2015.

Tabela 8: Saldo de transferências dos estados das regiões Norte, Nordeste e Centro-Oeste (em R\$ milhões)

\begin{tabular}{|c|c|c|c|c|c|c|c|c|c|c|c|}
\hline Ano & AC & AL & AM & AP & BA & CE & DF & GO & MA & MS & TOTAL \\
\hline 2002 & 769 & & 07 & 654 & & 1.403 & & 326 & & 83 & \\
\hline 2003 & 793 & 582 & 367 & 839 & 1.440 & 917 & 757 & 96 & 246 & 60 & .097 \\
\hline 2004 & 875 & 744 & 508 & 932 & 1.282 & 746 & 749 & 178 & 1.884 & 46 & 7.944 \\
\hline 2005 & 1.155 & 1.301 & 650 & 1.182 & 2.571 & 1.134 & 1.268 & 400 & 2.316 & $\overline{78}$ & 12.054 \\
\hline 2006 & 272 & 1.416 & 851 & 1.284 & 2.885 & 1.134 & 1.535 & 373 & 2.426 & $\overline{70}$ & 13.246 \\
\hline 2007 & 484 & 1.653 & 990 & 1.522 & 3.445 & 1.582 & 1.684 & 635 & 2.855 & 49 & 15.899 \\
\hline 2008 & 855 & 1.980 & 1.255 & 1.874 & 4.258 & 2.094 & 2.113 & 896 & 3.615 & 90 & 20.030 \\
\hline 2009 & 1.848 & 1.947 & 982 & 1.810 & 4.821 & 1.962 & 2.265 & 898 & 3.697 & 162 & 20.391 \\
\hline 2010 & 1.998 & 2.064 & 100 & 2.003 & 5.291 & 1.907 & 2.374 & 765 & 3.887 & 161 & 21.549 \\
\hline 2011 & 2.438 & 2.550 & .333 & 2.400 & 6.225 & 2.656 & 2.630 & 408 & 4.939 & 198 & 28.778 \\
\hline 2012 & 2.533 & 2.634 & 1.448 & 2.496 & 6.773 & 4.129 & 2.912 & 3.647 & 4.977 & 165 & 31.713 \\
\hline 2013 & 2.748 & 2.766 & 1.834 & 2.688 & 6.481 & 4.224 & 3.070 & 3.758 & 5.260 & -11 & 32.819 \\
\hline 2014 & 2.472 & 2.427 & 1.558 & 2.395 & 5.511 & 3.368 & 1.618 & 3.758 & 4.485 & -212 & 27.380 \\
\hline 2015 & 2.575 & 2.513 & 1.764 & 2.431 & 5.388 & 3.551 & 7.828 & 3.988 & 4.691 & -242 & 34.488 \\
\hline Ano & MT & PA & PB & PE & PI & RN & RO & RR & SE & TO & TOTAL \\
\hline 2002 & 120 & 1.292 & 979 & 1.146 & 982 & 809 & 453 & 589 & 920 & 952 & 8.241 \\
\hline 2003 & -118 & 1.231 & 973 & 1.171 & 958 & 794 & 549 & 607 & 782 & 952 & 7.900 \\
\hline 2004 & 234 & 1.503 & 1.103 & 1.411 & 933 & $\overline{944}$ & 617 & 686 & 920 & 1.076 & 9.428 \\
\hline 2005 & 499 & 1.865 & 1.447 & 1.937 & 1.344 & 1.416 & 781 & 862 & 1.251 & 1.546 & 12.947 \\
\hline 2006 & 507 & 2.000 & 1.586 & 2.105 & 1.462 & 1.529 & 868 & 941 & 1.351 & 1.608 & 13.956 \\
\hline 2007 & 615 & 2.427 & 1.819 & 2.537 & 1.990 & 1.741 & 1.055 & 1.100 & 1.588 & 1.781 & 16.653 \\
\hline 2008 & $\overline{979}$ & 3.232 & 2.287 & 3.317 & 2.586 & 2.205 & 1.299 & 1.351 & 2.034 & 2.443 & 21.733 \\
\hline 2009 & 926 & 3.190 & 2.863 & 3.444 & 2.703 & 2.069 & 1.282 & 1.323 & 2.059 & 2.226 & 22.084 \\
\hline 2010 & 1.028 & 3.568 & 3.082 & 3.458 & 3.003 & 2.364 & 1.338 & 1.442 & 2.271 & 2.537 & 24.091 \\
\hline 2011 & 1.262 & 4.269 & 3.713 & 4.307 & 3.505 & 2.643 & 1.679 & 4.301 & 3.286 & 2.997 & 31.961 \\
\hline 2012 & 1.206 & 4.366 & 3.840 & 4.433 & 3.660 & 2.751 & 1.686 & 1.767 & 3.466 & 3.047 & 30.222 \\
\hline 2013 & 2.952 & 4.438 & 4.142 & 4.574 & 3.824 & 2.911 & 1.844 & 1.908 & 3.686 & 3.359 & 33.639 \\
\hline 2014 & 3.064 & 3.744 & 3.842 & 3.907 & 3.387 & 3.141 & 1.617 & 1.689 & 3.318 & 2.689 & 30.398 \\
\hline 2015 & 3.081 & 3.772 & 4.019 & 4.228 & 3.498 & 2.456 & 2.612 & 1.769 & 3.317 & 3.062 & 31.813 \\
\hline
\end{tabular}

Fonte: Secretaria do Tesouro Nacional. Elaborada pelos autores.

Dessa maneira, ao contrário do que ocorre com os estados das regiões Sul e Sudeste, o sistema de transferências intergovernamentais amplia sensivelmente o saldo fiscal dos estados das Regiões Norte, Nordeste e Centro-Oeste, atuando como uma importante fonte de recursos para os mesmos.

\section{Análise Empírica}

\subsection{Modelo econométrico e dados}

Estimamos a função de reação fiscal desenvolvida por Bohn $(1998,2008)$, que assume a seguinte forma: 


$$
\begin{aligned}
\text { SuperávitprimárioPIB }_{i j t} & =\alpha_{j} \text { dividapúblicaPIB } B_{i t-1} \\
& +\sum_{1} \beta_{j 1} Z_{i t}+\eta_{i}+\varepsilon_{t}+u_{i j t}
\end{aligned}
$$

Em que a variável dependente é a razão superávit primário/PIB $j$ do estado $i$ no período $t$; divida pública é a dívida pública/PIB do estado $i$ no período $t-1$; o vetor $Z_{i t}$ inclui as variáveis que medem as flutuações do ciclo econômico e as despesas governamentais temporárias; $\eta_{i}$ são os efeitos fixos para os estados; $\varepsilon_{t}$ são os efeitos fixos de tempo e $u_{i j t}$ é o termo de erro.

Usamos duas medidas de saldo primário $(j=2)$. A primeira é a medida de saldo primário padrão (SP1), enquanto a segunda medida corresponde ao saldo primário padrão desconsiderando-se os pagamentos e recebimentos de transferências (SP2).

O parâmetro de interesse é $\alpha_{j}$. Bohn $(1998,2008)$ argumenta que quando o superávit primário no período $t$ responde positivamenteà razão dívida/PIB no período $t-1$ o governo adota uma política fiscal sustentável. Um sinal positivo de $\alpha_{j}$ indica que o governo toma medidas corretivas, aumentando receitas e/ou reduzindo despesas, a fim de neutralizar a acumulação da dívida pública.

As variáveis que medem as flutuações ciclo econômico e as despesas temporárias do governo são ${ }^{6}$ :

1. Indicadores do ciclo de negócios e do nível de gastos temporários do governo, representados por YVAR e GVAR. Barro (1986) define $Y V A R=$ $\left(1-y_{t} / y_{t T}\right) *\left(g_{t T} / y_{t}\right)$ e $G V A R=\left(g_{t}-g_{t T}\right) / y_{t}$, em que $y_{t}$ e $g_{t}$ descrevem os valores do PIB real e das despesas reais e $y_{t T}$ e $G_{t T}$ descrevem os valores de tendência do PIB real e das despesas reais.

A variável YVAR mede o desvio relativo do produto real com relação à sua tendência ponderado por $\left(g_{t} T / y_{t}\right)$. A variável GVAR mede os gastos acima da sua tendência. Valores positivos de YVAR indicam que o produto real está abaixo da sua tendência, enquanto valores positivos de GVAR indicam despesas reais acima da tendência.

2. Hiato do Produto definido como a diferença entre o logaritmo do valor efetivo do PIB real e a tendência do logaritimo do PIB real e o hiato da despesas definido como a diferença entre o logaritmo do valor efetivo das despesas e o valor de tendência do logaritmo das despesas. Um valor positivo do hiato do produto indica que o produto está acima da tendência, enquanto um valor positivo do hiato das despesas indica que as despesas estão acima da tendência.

O hiato das despesas deve ter um efeito negativo sobre o superávit primário, assim como YVAR e GVAR. Se o produto está abaixo da sua tendência, o superávit primário deve cair, ocorrendo o oposto quando o produto está acima da sua tendência. Assim, o hiato do produto deve influenciar positivamente o superávit primário.

${ }^{6}$ O modelo de suavização de impostos de Barro (1979) implica que, além da dívida, o superávit primário é determinado por um indicador do ciclo econômico e pelos gastos temporários do governo. Bohn (2008), por sua vez, usa o hiato do produto e o hiato das despesas. 
As estimações são feitas usando como amostra todos os estados brasileiros no período de 2001 a $2015^{7}$. A análise começa em 2001 porque a ideia é verificar o comportamento mais recente das dívidas estaduais, depois de promovidos os ajustes representados pela renegociação das dívidas em 1997 e pela implementação da Lei de Responsabilidade Fiscal em 2000.

No site da STN, são divulgadas diversas informações sobre os relatórios de gestão fiscal dos estados. Por meio deles, foram obtidos dados anuais sobre a Dívida Consolidada Líquida (DCL) dos estados e do Distrito Federal, além das informações sobre a execução orçamentária, como as receitas e despesas anuais totais e sua composição (próprias e de transferências).

Por fim, junto ao site do IBGE foram obtidos os dados anuais sobre o PIB de cada uma das 27 unidades federativas.

\subsection{Resultados}

Como explicitado anteriormente, o artigo tem como objetivo verificar se a razão dívida/PIB no período $t-1$ tem um efeito positivo sobre o superávit primário/PIB no período $t$ usando uma função de reação fiscal.

A Tabela 9 mostra os resultados das regressões quando a variável dependente é o saldo primário padrão (Saldo Primário 1 - SP1). O Modelo 1 usa como medidas das flutuações do ciclo econômico e do gasto temporário do governo as variáveis YVAR e GVAR, enquanto o Modelo 2 usa as variáveis hiato do produto e hiato das despesas.

Os resultados mostram que a razão superávit primário/PIB no período $t$ cai cerca de 0,003 pontos percentuais quando a razão dívida/PIB no período $t-1$ aumenta em 1 ponto percentual em ambos os modelos. O coeficiente estimado, entretanto, não é estatisticamente significante.

A relação negativa e não significante entre a dívida pública no período $t-1$ e o saldo primário (medida usual) no período $t$ no Modelo 1 e no Modelo 2 indica a ausência de sustentabilidade fiscal no período analisado.

De acordo com o esperado, YVAR e GVAR têm uma influência negativa (estatisticamente significante) sobre o superávit primário, implicando que o superávit cai quando a produção está abaixo da sua tendência, o mesmo ocorrendo quando o gasto público está acima da sua tendência.

As variáveis hiato do produto e hiato da despesa são estatisticamente significantes e apresentam os sinais corretos (o hiato do produto possui influência positiva sobre o superávit primário e o hiato das despesas influência negativa).

A Tabela 10 mostra os resultados das regressões quando a variável dependente é o saldo primário, excluindo-se as receitas e as despesas dos estados com transferências intergovernamentais (Saldo Primário 2 - SP2).

O Modelo 1 mostra que a variável dívida/PIB $B_{t-1}$ não possui significância estatística, embora seu sinal tenha mudado de negativo para positivo. As variáveis YVAR e GVAR são estatisticamente significantes ao nível de $1 \%$ e apresentam os sinais esperados.

O Modelo 2 também não apresenta evidências de sustentabilidade da dívida pública, ainda que as variáveis hiato do produto e hiato das despesas sejam estatisticamente significantes ao nível de $1 \%$ e tenham os sinais corretos.

\footnotetext{
${ }^{7}$ Dados anuais captando anos orçamentários são mais adequados do que dados de frequência mais alta quando se quer avaliar respostas à política fiscal.
} 
Tabela 9: Resultados das regressões para a variável dependente SP1

\begin{tabular}{l|c|c}
\hline Variáveis & Modelo 1 & Modelo 2 \\
\hline C & $0,006^{*}$ & $0,006^{*}$ \\
Dívida Pública/PIB $t-1$ & $(0,003)$ & $(0,003)$ \\
YVAR & $-0,033$ & $-0,032$ \\
& $-0.027)$ & $(0,026)$ \\
GVAR & $-0,737^{*}$ & \\
Hiato do Produto & $-1,501)$ & \\
Hiato das Despesas & $(0,483)$ & $0,028^{* *}$ \\
& & $(0,011)$ \\
Efeito-Fixo de Tempo & & $-0,061^{* *}$ \\
Efeito-Fixo de Estado & & $(0,020)$ \\
\hline R-Quadrado & Sim & Sim \\
\hline Número de Estados & Sim & 0,467 \\
Número de Observações & 27 & 27 \\
\hline Num & 405 & 405 \\
\hline
\end{tabular}

Nota: Erros-padrão robustos a autocorrelação e heterocedasticidade entre parênteses.

${ }_{* *}^{*} e^{*}$ denotam significância estatística aos níveis de $1 \%$ e $5 \%$, respectivamente.

Tabela 10: Resultados das regressões para a variável dependente SP2

\begin{tabular}{l|c|c}
\hline Variáveis & Modelo 1 & Modelo 2 \\
\hline C & $-0,061^{* *}$ & $-0,061^{* *}$ \\
Dívida Pública/PIB $t-1$ & $(0,003)$ & $(0,003)$ \\
& 0,014 & 0,014 \\
YVAR & $(0,031)$ & $(0,031)$ \\
& $-3,054^{* *}$ & \\
GVAR & $(0,636)$ & \\
Hiato do Produto & $-1,762^{* *}$ & \\
Hiato das Despesas & $(0,545)$ & $0,113^{* *}$ \\
& & $(0,024)$ \\
Efeito-Fixo de Tempo & & $-0,068^{* *}$ \\
Efeito-Fixo de Estado & & $(0,023)$ \\
R-Quadrado & Sim & Sim \\
\hline Número de Estados & Sim & 0,957 \\
Número de Observações & 0,958 & 27 \\
\hline Nut Erospado & 27 & 405 \\
\hline
\end{tabular}

Nota: Erros-padrão robustos a autocorrelação e heterocedasticidade entre parênteses.

** $\mathrm{e}^{*}$ denotam significância estatística aos níveis de $1 \%$ e 5\%, respectivamente. 
As transferências fiscais, assim, não parecem ser importantes para garantir a sustentabilidade fiscal dos estados brasileiros. Esse resultado difere dos encontrados por Madhavi \& Westlund (2011) e Potrafke \& Reischmann (2015), que apontam que as transferências são fundamentais para o equilíbrio intertemporal do orçamento nos Estados Unidos e na Alemanha.

O uso dos gastos totais para calcular a variável hiato da despesa, assim como a presença do hiato do produto nas regressões, pode levar a suspeita de endogeneidade que comprometeria as estimações. Diante disso, são feitas novas estimações excluindo-se as variáveis YVAR e GVAR, ou o hiato do produto e o hiato das despesas. Os resultados são apresentados na Tabela 11 e revelam que incluir/excluir as variáveis que medem o ciclo econômico e os gastos temporários do governo não afeta os resultados.

Tabela 11: Resultados das regressões para a variáveis SP1 e SP2, excluindo as variáveis de controle

\begin{tabular}{l|c|c}
\hline Variáveis & SP1 & SP2 \\
\hline C & $0,005^{* *}$ & $-0,062^{* *}$ \\
& $(0,003)$ & $(0,004)$ \\
Dívida Pública/PIB $B_{t-1}$ & $-0,024$ & 0,018 \\
& $(0,024)$ & $(0,034)$ \\
& Sim & Sim \\
Efeito-Fixo de Tempo & Sim & Sim \\
Efeito-Fxo de Estado & 0,417 & 0,954 \\
\hline R-Quadrado & 27 & 27 \\
Número de Estados & 405 & 405 \\
Número de Observações & \multicolumn{2}{|c}{} \\
\hline \multicolumn{2}{|c}{ Nota: Erros-padrão robustos a autocorrelação e heterocedasticidade entre } \\
parênteses. \\
** e denotam significância estatística aos níveis de 1\% e 5\%, respectivamente.
\end{tabular}

$\mathrm{Na}$ ausência de instrumentos adequados, outra possibilidade para lidar com o potencial problema de endogeneidade envolve usar como instrumentos variáveis internas ao painel, ou seja, as defasagens temporais das supostas variáveis endógenas. Assim, estimamos novamente o painel usando o método generalizado dos momentos (GMM - Generalized Method of Moments). Os resultados não se alteram ${ }^{8}$.

\section{Heterogeneidade}

Os resultados apresentados anteriormente podem esconder eventuais heterogeneidades. Como visto na Seção 2, os estados das regiões Sudeste e Sul são em geral pagadores líquidos de transferências, ou seja, pagam mais transferências do que recebem. O oposto ocorre com os estados das regiões Norte, Nordeste e Centro-Oeste que se beneficiam liquidamente de transferências.

Diante disso, reestimamos todos os modelos para os dois grupos de estados.

\footnotetext{
${ }^{8}$ A avaliação da presença de efeitos heterogêneos envolve, obviamente, a estimação de painéis com menos unidades de cross-section. Com isso não é possível fazer as estimações usando GMM. Para homogeneizar a apresentação dos resultados, não são então apresentadas as estimativas para o conjunto de todos os estados. Os resultados podem, contudo, ser obtidos diretamente com os autores.
} 
Os resultados das estimações para os estados das regiões Sul e Sudeste são apresentados na Tabela 12 .

Tabela 12: Resultados das regressões para a variável SP1 - Estados do Sul e Sudeste

\begin{tabular}{l|c|c}
\hline Variáveis & Modelo 1 & Modelo 2 \\
\hline C & $-0,002$ & $-0,003$ \\
Dívida Pública/PIB $t-1$ & $(0,002)$ & $(0,003)$ \\
& 0,017 & 0,018 \\
YVAR & $(0,023)$ & $(0,023)$ \\
& $-1,063^{* *}$ & \\
GVAR & $(0,294)$ & \\
Hiato do Produto & $\left(0,750^{* *}\right.$ & \\
Hiato das Despesas & & $0,038^{* *}$ \\
Efeito-Fixo de Tempo & & $(0,010)$ \\
Efeito-Fixo de Estado & Sim & $\left(0,028^{* *}\right.$ \\
\hline R-Quadrado & Sim & Sim \\
\hline Número de Estados & 0,489 & 0,489 \\
Número de Observações & 7 & 7 \\
\hline \multicolumn{2}{c}{ Nota: Erros-padrão robustos a autocorrelação e heterocedasticidade entre } \\
parênteses. & 105 & 105 \\
\hline$*$ e denotam significância estatística aos níveis de 1\% e 5\%, respectivamente.
\end{tabular}

A variável dívida/PIB em $t-1$ não aparece como estatisticamente significante, evidenciando ausência de sustentabilidade fiscal. A variável YVAR e a variável GVAR são estatisticamente significantes ao nível de 1\% e apresentam o sinal correto. O Modelo 2 indica também que a dívida dos estados não é sustentável. As variáveis do hiato do produto e do hiato do gasto aparecem com os sinais esperados e são estatisticamente significantes.

A Tabela 13 apresenta os resultados para o saldo primário excluindo as transferências intergovernamentais.

Os resultados contrastam com os obtidos quando a variável dependente é o superávit primário usual. A variável dívida/PIB em $t-1$ afeta positiva e significativamente o saldo primário em $t$, indicando sustentabilidade da dívida. Os resultados mostram que se a razão dívida/PIB no período $t-1$ aumenta em 1 ponto percentual a razão saldo primário (exclusive transferências)/PIB no período aumenta aproximadamente 0,13 pontos percentuais. É possível concluir, assim, que uma vez que os estados das regiões Sul e Sudeste pagam mais transferências do que recebem, os seus orçamentos são prejudicados pelo sistema de transferências.

A Tabela 14 apresenta os resultados das estimações para os estados das regiões Norte, Nordeste e Centro-Oeste quando a variável dependente é o resultado primário usual.

Tanto no Modelo 1 quanto no Modelo 2, a variável dívida/PI $B_{t-1}$ não se mostra estatisticamente significante, ou seja, a condição de sustentabilidade não é aceita. A variável YVAR e a variável GVAR apresentam os sinais corretos e são estatisticamente significantes aos níveis de $5 \%$ e $1 \%$, respectivamente. 
Tabela 13: Resultados das regressões para a variável SP2 - Estados do Sul e Sudeste

\begin{tabular}{l|c|c}
\hline Variáveis & Modelo 1 & Modelo 2 \\
\hline C & $-0,017^{*}$ & $-0,017^{*}$ \\
Dívida Pública/PIB $B_{t-1}$ & $(0,007)$ & $(0,007)$ \\
& $0,129^{*}$ & $0,128^{*}$ \\
YVAR & $(0,057)$ & $(0,057)$ \\
& $-0,115$ & \\
GVAR & $(0,421)$ & \\
Hiato do Produto & 0,813 & \\
Hiato das Despesas & $(0,439)$ & 0,004 \\
& & $(0,015)$ \\
Efeito-Fixo de Tempo & & 0,031 \\
Efeito-Fixo de Estado & Sim & $(0,017)$ \\
\hline R-Quadrado & Sim & Sim \\
\hline Número de Estados & 0,611 & 0,612 \\
Número de Observações & 7 & 7 \\
\hline Nota: Erro-padro robus & 105 & 105 \\
\hline
\end{tabular}

Nota: Erros-padrão robustos a autocorrelação e heterocedasticidade entre parênteses.

${ }_{* *} \mathrm{e}^{*}$ denotam significância estatística aos níveis de $1 \%$ e $5 \%$, respectivamente.

Tabela 14: Resultados das regressões para a variável SP1 - Estados do Norte, Nordeste e Centro-Oeste

\begin{tabular}{l|c|c}
\hline Variáveis & Modelo 1 & Modelo 2 \\
\hline C & 0,007 & 0,006 \\
Dívida Pública/PIB $B_{t-1}$ & $-0,003)$ & $(0,003)$ \\
YVAR & $(0.029)$ & $-0,026$ \\
& $-1,024^{*}$ & $(0.029)$ \\
GVAR & $(0,398)$ & \\
Hiato do Produto & $-2,160^{* *}$ & \\
Hiato das Despesas & $(0,575)$ & $0,040^{* *}$ \\
& & $(0,015)$ \\
Efeito-Fixo de Tempo & & $-0,092^{* *}$ \\
Efeito-Fixo de Estado & Sim & $(0,025)$ \\
\hline R-Quadrado & Sim & Sim \\
\hline Número de Estados & 0,493 & 0,492 \\
Número de Observações & 19 & 19 \\
\hline Num Eros & 285 & 285 \\
\hline
\end{tabular}

Nota: Erros-padrão robustos a autocorrelação e heterocedasticidade entre parênteses.

** $\mathrm{e}^{*}$ denotam significância estatística aos níveis de $1 \%$ e $5 \%$, respectivamente. 
O hiato do produto e o hiato das despesas são ambos estatisticamente significantes ao nível de $1 \%$ e apresentam o sinal esperado.

A Tabela 15 mostra os resultados quando são desconsideradas as transferências intergovernamentais.

Tabela 15: Resultados das regressões para a variável SP2 - Estados do Norte, Nordeste e Centro-Oeste

\begin{tabular}{l|c|c}
\hline Variáveis & Modelo 1 & Modelo 2 \\
\hline C & $-0,085^{* *}$ & $-0,085^{* *}$ \\
Dívida Pública/PIB $t-1$ & $(0,004)$ & $(0,004)$ \\
YVAR & 0,017 & 0,017 \\
& $(0,034)$ & $(0,034)$ \\
GVAR & $-3,694^{* *}$ & \\
Hiato do Produto & $-2,774)$ & \\
Hiato das Despesas & $(0,595)$ & \\
Efeito-Fixo de Tempo & & $0,140^{* *}$ \\
Efeito-Fixo de Estado & & $(0,030)$ \\
\hline R-Quadrado & Sim & $\left(0,085^{* *}\right.$ \\
Número de Estados & Sim & Sim \\
\hline Número de Observações & 0,954 & Sim \\
\hline Nota: Erros-padrão robustos a autocorrelação e heterocedasticidade entre \\
parênteses. & 19 & 0,954 \\
$* *$ & e denotam significância estatística aos níveis de 1\% e 5\%, respectivamente.
\end{tabular}

Novamente, a condição de sustentabilidade fiscal não é aceita. No Modelo 1 e no Modelo 2, a relação dívida/PIB em $t-1$ não apresenta significância estatística. As variáveis YVAR e GVAR são estatisticamente significantes, assim como o hiato do produto e o hiato das despesas. Tanto as variáveis que descrevem as flutuações do ciclo econômico quanto as que captam os gastos temporários do governo apresentam os sinais esperados.

Para completar a análise, são apresentados na Tabela 16 os resultados das regressões sem as variáveis de controle para os estados das regiões Sul e Sudeste.

Os resultados mostram uma influência positiva da razão dívida/PIB no período $t-1$ sobre o superávit primário inclusive transferências, embora esta não seja estatisticamente significante. No entanto, depois que são excluídas as transferências, o efeito passa a ser estatisticamente significante.

$\mathrm{Na}$ Tabela 17, temos as regressões sem as variáveis de controle para os estados das regiões Norte, Nordeste e Centro-Oeste.

Os resultados das regressões para os Estados do Norte, Nordeste e CentroOeste indicam que quando a variável dependente é o superávit tradicional, o coeficiente da variável razão dívida/PIB é negativo e estatisticamente insignificante. Quando a variável dependente é o superávit primário exclusive as transferências, o coeficiente passa a ser positivo, de magnitude pequena, mas ainda estatisticamente insignificante. 
Tabela 16: Resultados das regressões para as variáveis SP1 e SP2, excluindo as variáveis de controle - Estados do Sul e Sudeste

\begin{tabular}{l|c|c}
\hline Variáveis & SP1 & SP2 \\
\hline C & $-0,005$ & $-0,013$ \\
Dívida Pública/PIB & $(0,005)$ & $(0,006)$ \\
& 0,033 & $0,095^{*}$ \\
& $(0,038)$ & $(0,045)$ \\
Efeito-Fixo de Tempo & Sim & Sim \\
Efeito-Fixo de Estado & Sim & Sim \\
\hline R-Quadrado & 0,394 & 0,595 \\
\hline Número de Estados & 7 & 7 \\
Número de Observações & 105 & 105 \\
\hline
\end{tabular}

Nota: Erros-padrão robustos a autocorrelação e heterocedasticidade entre parênteses.

** $e^{*}$ denotam significância estatística aos níveis de $1 \%$ e $5 \%$, respectivamente.

Tabela 17: Resultados das regressões para as variáveis SP1 e SP2, excluindo as variáveis de controle - Estados do Norte, Nordeste e Centro-Oeste

\begin{tabular}{l|c|c}
\hline Variáveis & SP1 & SP2 \\
\hline C & $0,006^{*}$ & $-0,085^{* * *}$ \\
Dívida Pública/PIB & $(0,003)$ & 0,017 \\
& $-0,018$ & $(0,036)$ \\
& $(0,024)$ & Sim \\
Efeito-Fixo de Tempo & Sim & Sim \\
Efeito-Fixo de Estado & Sim & 0,948 \\
\hline R-Quadrado & 0,424 & 19 \\
\hline Número de Estados & 19 & 285 \\
Número de Observações & 285 & \\
\hline
\end{tabular}

Nota: Erros-padrão robustos a autocorrelação e heterocedasticidade entre parênteses.

** $\mathrm{e}^{*}$ denotam significância estatística aos níveis de $1 \%$ e $5 \%$, respectivamente.

\section{Conclusão}

O objetivo deste artigo é verificar se a sustentabilidade fiscal dos estados brasileiros durante o período 2001 a 2015 é afetada pelo sistema de transferências intergovernamentais. Para avaliar a questão, é usado o modelo de Bohn, ou seja, é estimada uma função de reação fiscal em que uma resposta negativa da razão superávit primário/PIB à razão dívida/PIB indica fragilidade fiscal. São usadas duas medidas de saldo primário, uma incluindo e outra excluindo as receitas e despesas advindas das transferências entre os diferentes níveis de governo.

Quando se olha para o conjunto dos estados, o sistema de transferências não atua no sentido de subsidiar de forma implícita as dívidas estaduais. As evidências indicam que os governos estaduais não perseguem políticas fiscais sustentáveis, quer sejam incluídas ou excluídas as transferências fiscais.

Há, contudo, heterogeneidade na resposta da razão superávit primário/PIB à razão dívida/PIB, dependendo da importância líquida das transferências 
para o orçamento. Como os estados recebem transferências da União, mas também transferem recursos para os municípios, é possível dividi-los em dois grupos: estados das regiões Sul e Sudeste, que em geral transferem mais recursos do que recebem, e estados das regiões Norte, Nordeste e Centro-Oeste, que recebem mais recursos do que transferem. Diante disso, espera-se que para o primeiro grupo, o sistema de transferências prejudique o desempenho fiscal, enquanto para o segundo grupo melhore.

A evidência empírica obtida indica que o sistema de transferências dificulta a avaliação da sustentabilidade fiscal dos estados das regiões Sul e Sudeste, uma vez que quando as transferências são incluídas, a política fiscal aparece como insustentável, ao passo que, quando as transferências são excluídas, a política fiscal passa a ser sustentável. No caso dos estados das regiões Norte, Nordeste e Centro-Oeste, o sistema de transferências não afeta os resultados. Os estados apresentam situação fiscal bastante preocupante, uma vez que nem mesmo se beneficiando liquidamente de transferências conseguem apresentar um desempenho fiscal adequado.

Esses resultados diferem dos encontrados na escassa literatura que trata da mesma questão para outras federações (Madhavi \& Westlund 2011, Potrafke \& Reischmann 2015). Somente quando as transferências são incluídas, as políticas fiscal dos estados americanos e alemão são sustentáveis, o que implica que o sistema de transferências faz com que os orçamentos estaduais pareçam melhores do que realmente são.

Postali \& Rocha (2003) indicam que o sistema de transferências intergovernamentais tem direcionado recursos dos estados mais ricos para os mais pobres, atuando como um esquema de seguro regional contra o risco. Aqui observa-se que esse esquema de seguro, no entanto, parece vir à custa da não sustentabilidade da política fiscal dos estados mais ricos sem que, contudo, seja garantida a sustentabilidade da política fiscal dos estados mais pobres. Esse resultado é mais um que coloca dúvidas sobre o atual desenho do sistema de transferências intergovernamentais no Brasil e chama a atenção para a necessidade de mecanismos que alinhem corretamente os incentivos dos diferentes entes federativos.

\section{Referências Bibliográficas}

Ahmed, S. \& Rogers, J. H. (1995), 'Government budget deficits and trade deficits: are present value constraints satisfied in long-term data?', Journal of Monetary Economics 36, 351-374.

Barro, R. J. (1979), 'On the determination of the public debt', Journal of Political Economy 87, 940-971.

Barro, R. J. (1986), 'U.S. deficits since World War I', Scandinavian Journal of Economics 88, 195-222.

Bicalho, A. \& Issler, J. (2011), 'Teste de sustentabilidade da dívida, ajuste fiscal no Brasil e consequências para o produto', Departamento de Pesquisa Macroeconômica Itaú Unibanco . Textos para Discussão.

Bohn, H. (1998), 'The behavior of U.S. public debt and deficits', Quarterly Journal of Economics 113, 949-963. 
Bohn, H. (2007), 'Are stationarity and cointegration restrictions really necessary for the intertemporal budget constraint?', Journal of Monetary Economics 54(7), 1837- 1847.

Bohn, H. (2008), The sustainability of fiscal policy in the United States, in: R. Neck and J. Sturm, Sustainability of public debt, MIT Press.

Byrne, J. P., Fiess, N. \& MacDonald, R. (2011), 'The global dimension to fiscal sustainability', Journal of Macroeconomics 33, 137-150.

Chicoli, R. S. (2015), Sustentabilidade da dívida pública brasileira: uma análise sob diversos conceitos de superávit primário e endividamento, $\mathrm{PhD}$ thesis, Dissertação de Mestrado. IPE-USP. Faculdade de Economia, Administração e Contabilidade da USP.

Fincke, B. \& Greiner, A. (2011), 'Debt sustainability in Germany: empirical evidence for federal states', International Journal of Sustainable Economy 3, 235-254.

Ghosh, A. R., Kim, J. I., Mendoza, E. G., Ostry, J. D. \& Qureshi, M. S. (2013), 'Fiscal fadigue, fiscal space and debt sustainability in advanced economies', Economic Journal 123, F4-F30.

Hakkio, C. \& Rush, M. (1991), 'Is the budget deficit too large?', Economic Inquiry 29, 429-445.

Hamilton, J. D. \& Flavin, M. A. (1986), 'On the limitations of government borrowing: a framework for empirical testing', American Economic Review 76(4), 808-819.

Issler, J. V. \& Lima, L. R. (2000), 'Public debt sustainability and endogeneous seigniorage in Brazil: Time-series evidence from 1947-92', Journal of Development Economics 62(1), 131-147.

Koester, G. B. \& Priesmeier, C. (2013), 'Does Wagner's Law ruin the sustainability of German public finances? ', Finanz Archiv: Public Finance Analysis 69, 256-288.

Luporini, V. (2002), 'The behavior of the Brazilian federal domestic deficit', Economia Aplicada pp. 713-733.

Luporini, V. (2015), 'Sustainability of Brazilian fiscal policy, once again: corrective policy response over time', Estudos Econômicos 45(2), 437-458.

Madhavi, S. \& Westlund, J. (2011), 'Fiscal stringency and fiscal sustainability: panel evidence from the American state and local governments', Journal of Policy Modeling 33, 953-969.

Mello, L. (2008), 'Estimating a fiscal reaction function: the case of debt sustainability in Brazil', Applied Economics 40, 271- 284.

Mendes et. al., M. (2008), 'Transferências intergovernamentais no Brasil: Diagnóstico e proposta de reforma', Consultoria Legislativa do Senado Federal . Textos para discussão: $\mathrm{n}^{\circ} 40$. 
Mendonça et. al., M. (2009), 'Revisitando a função de reação fiscal no Brasil pós Real: Uma abordagem de mudanças de regime', Estudos Econômicos 39(4).

Mendoza, E. G. \& Ostry, J. D. (2008), 'International evidence on fiscal solvency: is fiscal policy 'responsible'?', Journal of Monetary Economics 55, 10811093.

Mora, M. \& Giambiagi, F. (2007), 'Federalismo e endividamento subnacional: uma discussão sobre a sustentabilidade da dívida estadual', Revista de Economia Política 27(3), 472-494.

Pastore, A. C. (1995), 'Déficit público, a sustentabilidade do crescimento das dívidas interna e externa, senhoriagem e inflação: Uma análise do regime monetário brasileiro', Revista de Econometria 14(2), 177-234.

Pereira, J. (2008), Sustentabilidade da dívida pública dos estados brasileiros, PhD thesis, Dissertação de Mestrado. UFMG/CEDEPLAR.

Postali, F. \& Rocha, F. (2003), 'Federalismo fiscal enquanto esquema de seguro regional: uma avaliação do caso brasileiro', Pesquisa e Planejamento Econômico 33(3).

Potrafke, M. \& Reischmann, M. (2015), 'Fiscal transfers and fiscal sustainability', Journal of Money, Credit and Banking 47(5), 975-1005.

Prohl, S. \& Westerlund, J. (2009), 'Using panel data to test for fiscal sustainability within the European Union', Finanz Archiv: Public Finance Analysis 65, 246-269.

Quintos, C. E. (1995), 'Sustainability of the deficit process with structural shifts', Journal of Business E Economics Statistics 13, 409-417.

Rocha, F. (1997), 'Long-run limits on the Brazilian government debt', Revista Brasileira de Economia 51, 447-470.

Simonassi, A. (2007), Função de resposta fiscal, múltiplas quebras estruturais e a sustentabilidade da dívida pública no Brasil, XXXV encontro da ANPEC, Recife-PE.

Tabosa et. al., F. (2016), 'Reação fiscal ao aumento da dívida pública: uma análise para os estados brasileiros', Economia Aplicada 20(1), 57-71.

Ter-Minassian, T. (2012), 'Reform priorities for sub-national revenues in Brazil'. IDB Working Paper, IDB-PB-157.

Trehan, B. \& Walsh, C. (1988), 'Common trends, the government budget constraint, and revenue smoothing', Journal of Economic Dynamic and Control 12, 425-444.

Trehan, B. \& Walsh, C. (1991), 'Testing intertemporal budget constraints: Theory and applications to US federal budget and current account deficits', Journal of Money, Credit and Banking 23, 206-223.

Wilcox, D. (1989), 'The sustainability of government deficits: implications of the present-value borrowing constraints', Journal of Money, Credit and Banking, Columbus 21(3), 291-306. 